\title{
Audio/Video Selector 5 Channel dengan Menggunakan Program Mikrokontroler AT89C2051
}

\author{
Mhd Erpandi Dalimunthe* \\ Program Studi Teknik Elektro, Fakultas Sains dan Teknologi, Universitas Pembangunan Panca Budi \\ *Corresponding email: erpandi@dosen.pancabudi.ac.id
}

\begin{abstract}
Abstrak- Audio / Video Selector 5 Channel dengan Mikrokontroler AT89C2051 adalah suatu alat yang digunakan untuk memilih salah satu peralatan elektronik audio / video seperti DVD player, VCD player, Playstasion untuk diaktifkan. Alat ini menggunakan mikrokontroler AT89C2051 yang telah diprogram sebagai pusat kontrol dari rangkaian audio / video selector 5 channel dengan menekan remote sebagai pengendali. Input dari alat tersebut dihubungkan ke beberapa peralatan elektronik dan outputnya dihubungkan ke pesawat televisi. Alat tersebut memberikan kemudahan bagi pemilik pesawat televisi yang hanya memiliki satu input jack A/V.
\end{abstract}

\section{Kata Kunci : Remote Kontrol, AT89C2051, Relay}

Abstract-Audio / Video Selector 5 Channel with Microcontroller AT89C2051 is a tool used to select one of the audio / video electronic equipment such as DVD player, VCD player, Playstation to be activated. This tool uses the AT89C2051 microcontroller which has been programmed as the control center of the 5 channel audio/video selector circuit by pressing the remote as the controller. The input of the device is connected to several electronic equipment and the output is connected to a television set. This tool makes it easy for owners of television sets that only have one A/V jack input.

Keywords : Remote Control, AT89C2051, Relay

\section{PENDAHULUAN}

Dengan kemajuan teknologi saat ini, semua perangkat elektronika dikendalikan mengunakan suatu sistem yang canggih dan modern. Di zaman teknologi digital dan mikroprosesor, banyak perangkat atau hardware yang membuat manusia memiliki suatu aktifitas yang praktis dan cepat. Oleh karena itu, penulis berinisiatif akan membuat suatu alat yang digunakan untuk mengontrol semua perangkat elektronika yang berhubungan dengan audio/video yang dihubungkan ke pesawat televisi. Hanya dengan menekan remote sebagai pengendali alat tersebut, semua perangkat elektronika dapat diaktifkan dengan mengunakan arah atau navigator tehadap posisi perangkat elektronik yang akan diaktifkan maupun dinonaktifkan [3]. Alat audio/video dengan mengunakan remote kontrol ini sangat membantu bagi masyarakat atau konsumen pemakai alat tersebut, karena praktis dan efisien serta modern. Hanya dengan mengunakan satu sumber output yang dihubungkan pada A/V yang dimiliki pesawat televisi dengan lima sumber input audio/video yang digunakan untuk perangkat elektronik seperti DVD player, VCD Player, Playstasion dan perangkat elektronik lainnya yang berhubungan dengan audio/video.

Relay pada alat audio/video ini berfungsi sebagai selector aktif 5 channel $\mathrm{A} / \mathrm{V}$ pada sumber masukan perangkat elektronik [6]. Remote yang digunakan adalah remote yang bekerja pada frekuensi kurang lebih 40 KHz. Pada rangkaian audio/video selector 5 channel dengan mikrokontroler AT89C2051 ini, mengunakan remote sony RM S-190 sebagai transmitter atau pemancar. Sumber tegangan yang digunakan adalah 12 Volt dari rangkian penyearah atau rectifier dua fase untuk rangkaian relay, seven segment dan kipas, serta 5 Volt untuk IC Mikrokontroler AT89C2051.

\section{TINJAUAN PUSTAKA}

Nilai potensial listrik (V) juga berhubungan erat dengan kerapatan flux listrik (D). Pada umumnya resistansi didefinisikan sebagai sesuatu yang melawan arus dan dinyatakan dalam satuan ohm $(\Omega)$ [2]. Bentukbentuk resistor konvensional mengikuti suatu "hukum garis lurus" (staright line law) ketika tegangan diplot terhadap arus dan ini memungkinkan kita menggunakan resistor sebagai suatu sarana untuk mengkonversi arus menjadi jatuh tegangan, dan sebaliknya [7]. Kapasitor adalah perangkat yang digunakan untuk menyimpan muatan listrik [5]. Sebagai akibatnya kapasitor merupakan suatu tempat penampungan (reservoir) dimana muatan dapat disimpan kemudian di ambil kembali. Aplikasi- aplikasi yang umum meliputi kapasitor penampung dan kapasitor penghalus yang digunakan dalam catu daya, pencampuran sinyal-sinyal AC diantara tahapan-tahapan (stages) amplifier, dan pemisah sinyal-sinyal dalam catu daya.

Sebuah dioda ideal akan melewatkan arus tak terhingga pada satu arah dan sama sekali tidak melewatkan arus pada arah sebaliknya [2]. Sebagai tambahan, dioda akan mulai mengalirkan arus apabila tegangan terkecil sekalipun diberikan. Dalam prakteknya, suatu tegangan yang sangat kecil harus diberikan sebelum aliran arus terjadi. Lebih jauh lagi, 
arus bocor yang kecil akan mengalir pada arah mundur. Arus bocor ini biasanya merupakan pecahan yang sangat kecil dari arus yang mengalir pada arah majunya.

Transistor digolongkan ke dalam dua kategori (bipolar dan efek-medan) dan juga di kelompokkan menurut bahan semikonduktor yang digunakan untuk membuatnya (silikon atau germanium) dan menurut bidang aplikasinya (misalnya serbaguna, pensaklaran, frekwensi tinggi, dll) [6]. Transistor sebagai saklar sering digunakan untuk mengontrol arus yang lebih besar atau sebagai penyangga dari rangkaian yang bertegangan lebih besar ke yang bertegangan lebih kecil [7]. Transistor sebagai saklar dalam kondisi normalnya tidak diberi bias atau di katakan dalam keadaan mati. Jika tegangan masukan (Vi) cukup besar maka keadaannya akan berubah dari keadaan cut off ke keadaan jenuh. Keadaan jenuh terjadi saat Ic maksimum, sehingga kenaikan Ib tidak lagi menyebabkan kenaikan Ic. Pada kondisi ini Vc mendekati nol sehingga Vce seakan terhubung singkat ke tanah, hal ini disamakan dengan keadaan saklar tertutup.

Jenis memori yang dipakai untuk Memori Program AT89Cx051 adalah Flash PEROM, program untuk mengendalikan mikrokontroler diisikan ke memori itu lewat bantuan alat yang dinamakan sebagai AT89Cx051 Flash PEROM Programmer [1]. Memori Data yang disediakan dalam chip AT89Cx051 sebesar 128 byte, meskipun hanya kecil saja tapi untuk banyak keperluan memori kapasitas itu sudah mencukupi. Sarana Input/Output yang disediakan cukup banyak dan bervariasi. AT89Cx051 mempunyai 17 jalur Input/Output paralel. Jalur Input/Output paralel ini dikenal sebagai Port 1 (P1.0..P1.7) dan Port 3 (P3.0..P3.5 dan P3.7). AT89Cx051 dilengkapi UART (Universal Asynchronous Receiver / Transmiter) yang biasa dipakai untuk komunikasi data secara seri [4]. Jalur untuk komunikasi data seri (RXD dan TXD) diletakan berhimpitan dengan P1.0 dan P1.1 di kaki nomor 2 dan 3, sehingga kalau sarana UART ini dipakai maka P1.0 dan P1.1 tidak lagi bisa dipakai untuk jalur input/output paralel.

AT89Cx051 mempunyai 5 sumber pembangkit interupsi, 2 diantaranya adalah sinyal interupsi yang di umpankan ke kaki INT0 dan INT1, kedua kaki ini berhimpitan dengan P3.2 dan P3.3 sehingga tidak bisa dipakai sebagai jalur input/output paralel kalau INT0 dan INT1 dipakai untuk menerima sinyal interupsi. 3 sumber interupsi yang lain berasal dari sarana komunikasi data seri dan dari sistem Timer 0 dan Timer 1. Port 1, Port 2, UART, Timer 0, Timer 1 dan sarana lainnya merupakan register yang secara fisik merupakan RAM khusus, yang ditempatkan di Special Function Register (SFR).

Program untuk mengendalikan kerja dari mikrokontroler disimpan di dalam memori program. Program pengendali tersebut merupakan kumpulan dari instruksi kerja mikrokontroler, 1 instruksi MCS51 merupakan kode yang panjangnya bisa satu sampai empat byte [4]. Sepanjang mikrokontroler bekerja, instruksi tersebut diproses secara byte demi byte yang diambil ke CPU dan selanjutnya dipakai untuk mengatur kerja mikrokontroler. Proses pengambilan instruksi dari memori program dikatakan sebagai 'fetch cycles' dan saat-saat CPU melaksanakan instruksi disebut sebagai 'execute cycles'.

Semua mikrokontroler maupun mikroprosesor dilengkapi sebuah register yang berfungsi khusus untuk mengatur 'fetch cycles', register tersebut dinamakan sebagai Program Counter. Nilai Program Counter secara otomatis bertambah satu setiap kali selesai mengambil 1 byte isi memori program, dengan demikian isi memori program bisa berurutan diumpankan ke CPU [4].

Komponen utama dari sistem catu daya adalah transformator. Transformator adalah suatu device elektronika yang banyak dipakai untuk mentransfer tegangan AC dari suatu nilai tertentu menjadi tegangan AC yang bernilai lebih tinggi atau lebih rendah sesuai dengan perbandingan jumlah lilitannya [6]. Suatu transformator mempunyai $\mathrm{N}$ lilitan sehingga mempunyai perbandingan $\eta$, lilitan yang berhubungan dengan tegangan input disebut lilitan primer sedangkan yang berhubungan dengan tegangan output disebut lilitan sekunder.

Relay adalah suatu saklar (switch) elektrik yang bekerja berdasarkan medan magnet [5]. Susunan kontak pada relay adalah Normally Open : relay akan menutup bila dialiri arus listrik, Normally Close : relay akan membuka bila dialiri arus listrik, dan Change Over : relay akan memiliki kontak tengah yang akan melepaskan diri dan membuat kontak lainnya berhubungan.

\section{METODOLOGI}

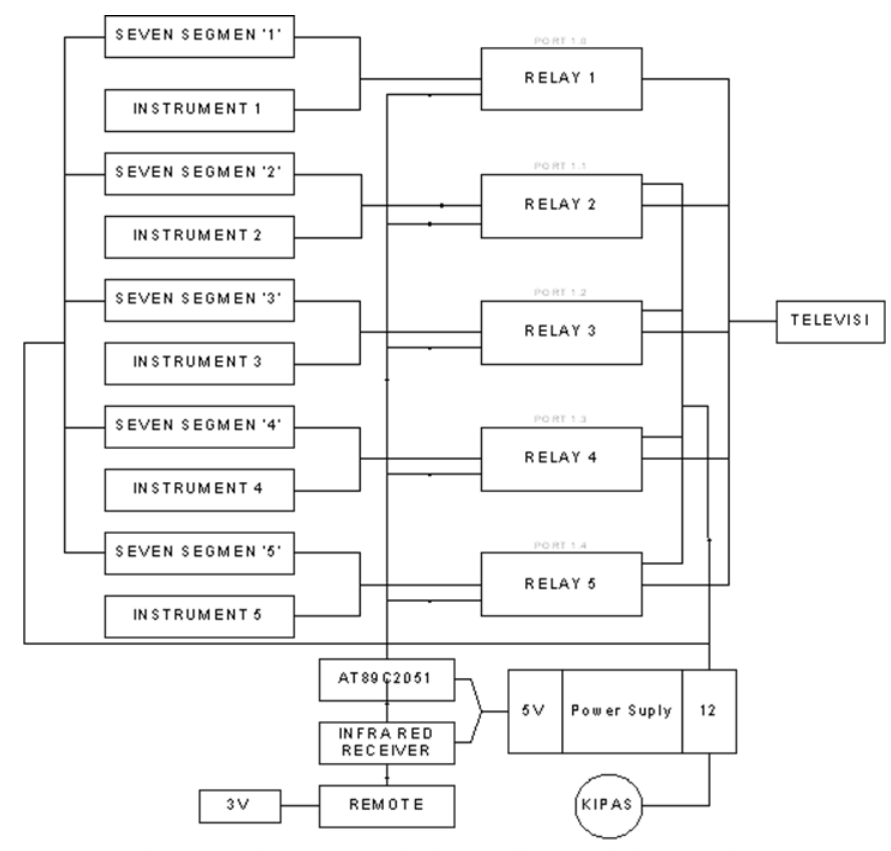

Gambar 1 Diagram Blok Audio / Video Selector 5 Channel Dengan Mikrokontroler AT89C2051 
Pada rangkaian audio / video selector 5 channel dengan mikrokontroler AT89C2051, memiliki dua sumber tegangan yang berbeda yaitu $5 \mathrm{~V}$ untuk IC AT89C2051, IRDA dan 12V untuk relay, seven segment, dan kipas. Dalam kondisi normal tegangan output IRDA (Infrared Receiver Data) pada kaki 2 akan sama dengan tegangan input IRDA (Infrared Receiver Data) pada kaki 3. dan kaki 3 sebagai ground. Output dari IC AT89C2051 yaitu kaki 12 atau port 1.0, kaki 13 atau port 1.1, kaki 14 atau port 1.2, kaki 15 atau port 1.3 dan kaki 16 atau port1.4 akan kondisi Low (0). Sehingga semua transistor akan cut off dan relay tidak akan aktif. Led pada seven segment akan padam [1].

Bila akan mengaktifkan rangkaian ini maka, yang harus diperhatikan adalah remote kontrol, apakah rusak atau baterai habis serta power suplay? Jika akan mengaktifkan salah satu A/V maka harus menekan tombol remote. Namun sebelumnya tombol remote telah di program oleh IC AT89C2051 terlebih dahulu . Pada alat ini untuk tombol 1 eksekusi port 1.0, tombol 2 eksekusi port 1.1, tombol 3 eksekusi port 1.2, tombol 4 eksekusi port 1.3 dan tombol 5 eksekusi port 1.4 serta tombol power eksekusi untuk semua port (P1.0 - P1.4). Apabila penulis akan menekan remote pada tombol 1 maka output IRDA(Infrared Receiver Data) pada kaki 2 akan berkurang $\pm 3,5 \mathrm{~V}$, awalnya tegangan input pada kaki 3 akan sama dengan kaki 2 pada output IRDA(Infrared Receiver Data) (lihat gambar 3.3). Kemudian akan kembali ke kondisi awal atau normal yakni kaki 2 sebagai output IRDA(Infrared Receiver Data) akan sama dengan kaki 3 sebagai input IRDA (Infrared Receiver Data) setelah penekanan remote usai. Tegangan akan masuk ke kaki 6 atau port 3.2 yakni INT1 pada mikrokontroler AT89C2051 dengan membawa data biner untuk melakukan eksekusi. Semua eksekusi dijalankan dan diatur oleh mikrokontroler yang telah di isi oleh sebuah program dalam bentuk heksa mengunakan bahasa asembler, kristal yang digunakan oleh rangkaian ini adalah 9,982 Mhz, yang berfungsi sebagai clock internal untuk sebuah generator gelombang persegi yang stabil dan akurat. Sehingga output pada mikrokontroler AT89C2051 tersebut adalah port 1.0 atau kaki 12 yang kemudian akan diteruskan kembali ke rangkaian relay.1.

Dikarenakan logika high (1) pada port 1.0 dengan level tegangan $\pm 4,5$ Volt maka akan menuju ke resistor $470 \Omega$. Resistor ini berfungsi sebagai pencegah arus yang berlebihan masuk ke dalam kaki basis pada transistor BD139. Sehingga kondisi ini membuat transistor akan saturasi atau diasumsikan bahwa antara kaki colektor dan kaki emitor seperti hubungan saklar tertutup. Hal tersebut akan membuat kondisi pada kaki kolektor menjadi low (0) dikarenakan kaki emitor terhubung oleh ground. Kondisi kolektor low (0) membuat relay1 akan aktif atau kondisi normaly open dengan kata lain relay akan menutup bila dialiri arus listrik. Relay yang digunakan adalah relay dengan jumlah switch 4 buah, dimana switch 1 untuk katoda pada seven segment dan anoda berasal dari titik A pada rangkaian power suplay dengan diberikan resistor $1 \mathrm{~K}$ sebagai penahan arus yang berlebihan. Kemudian led akan menyala menunjukan angka 1 (lihat gambar 3.5), switch 2 untuk input video 1 dari perangkat instrumentasi elektronik untuk pesawat televisi yang di beri jack warna kuning, switch 3 untuk input audio right / audio R1 dari perangkat instrumentasi elektronik untuk pesawat televisi yang diberi jack warna merah, switch 4 untuk input audio left / audio L1 dari perangkat instrumentasi elektronik untuk pesawat televisi yang diberi jack putih.

Cara kerja penekan remote pada tombol 1 di atas sama halnya dengan penekanan tombol 2 sampai dengan tombol 5. Bila tombol 1 sedang aktif, maka dapat mengaktifkan tombol 2 sehingga seven segmen akan menunjukkan angka 2 begitu pula dengan tombol 3, 4 dan 5. Bila penekanan remote pada tombol power, maka output pada port1.0 - port1.4 akan high (1) dengan level tegangan $\pm 4,5$ Volt. Saat tombol power ditekan kembali, maka output pada port 1.0 - port 1.4 akan low (0) dengan level tegangan $\pm 0,03 \mathrm{~V}$. Jadi saat rangkaian sedang aktif maka untuk menonaktifkan hanya dengan menekan tombol power dua kali.

\section{HASIL DAN PEMBAHASAN}

Adapun langkah - langkah yang harus diperhatikan, bila akan mengunakan alat Audio/Video Selector 5 Channel Dengan Mikrokontroler AT89C2051 adalah : 1. Pastikan remote control Sony RM S190 telah diberi baterai 3 Volt dan tidak rusak. 2. Pastikan posisi alat dari kelima input Audio/Video atau A/V terhubung pada instrument elektronik seperti VCD player, DVD Player ataupun Playstasion, dimana pada jack kuning sebagai video, jack merah sebagai audio right $(R)$, dan jack putih sebagai audio left $(L)$. 3. Pastikan output audio/video (A/V) terhubung pada pesawat televise, dimana jack kuning sebagai video, jack merah sebagai audio right $(R)$ dan jack putih sebagai audio left $(L)$. 4. Pastikan alat diberi tegangan 220 Volt AC, kemudian switch power regulator ditekan pada posisi on maka kipas dan led 1 menyala. 5. Penekanan tombol 1 pada remote control, maka audio / video pertama aktif dan seven segment akan menampilkan angka 1 dan seterusnya sampai pada penekanan tombol 5. 6. Penekanan tombol power dua kali maka seluruh audio/video akan tidak aktif. 


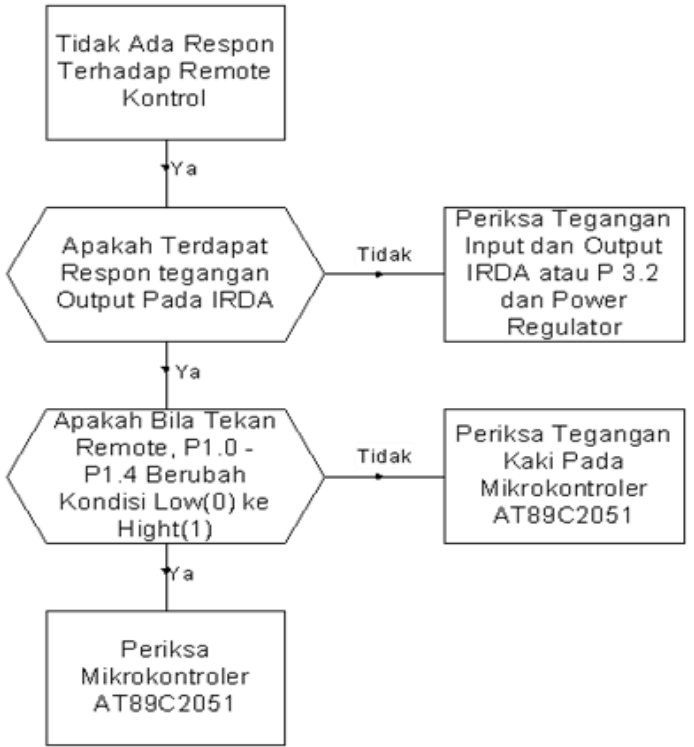

Gambar 2 Diagram Alur Alat Tidak Respon Terhadap Remote Control

Gambar 2 diatas menjelaskan gejala apabila saat menekan remote control, namun tidak ada respon dari receiver atau penerima dan seven segment tidak menyala. Hal ini disebabkan gangguan rusak pada remote control, infrared receiver sampai relay. Untuk solusi pencarian gangguannya dengan memeriksa remote control, apakah baterai habis? lalu periksa input dan output pada IRDA (Infrared Receiver Data). Apakah saat penekanan remote output IRDA pada kaki 2 mengalami penurunan tegangan hanya sesaat dan kemudian kembali ke semula. Dimana tegangan input akan sama dengan tegangan output. Serta output pada Port

1.0 sampai Port 1.4 mengalami perubahan dari kondisi low (0) ke high (1).

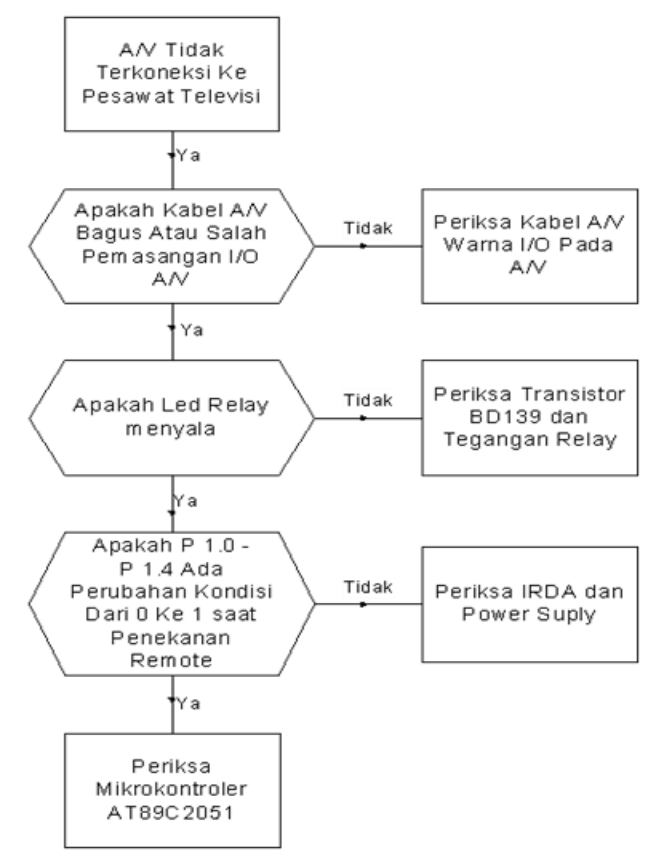

Gambar 3 Diagram Alur Audio/Video Tidak Terkoneksi Pada Pesawat Televisi
Gambar 3 menjelaskan gejala instrument elektronik seperti DVD Player, VCD Player ataupun Playstation, tidak tampak gambar dan suara pada pesawat televisi. Penyebab gangguan pada umumnya kerusakan pada kabel $\mathrm{A} / \mathrm{V}$ atau pemasangan input/output tidak sesuai, relay tidak aktif. Solusi pencarian gangguan dengan melakukan pemeriksaan kabel $\mathrm{A} / \mathrm{V}$ yang terhubung antara alat audio / video selector 5 channel dengan instrument elektronik dan juga kabel $\mathrm{A} / \mathrm{V}$ yang terhubung antara alat audio / video selector 5 channel dengan pesawat televisi. Dimana pada alat audio / video input atau output untuk warna kuning sebagai video, warna merah sebagai audio right/ audio $\mathrm{R}$, dan warna putih sebagai audio left / audio L. Kemudian periksa tegangan IC AT89C2051 pada kaki 20, apakah ada tegangan volt pada titik B (lihat gambar 4.3) Periksa rangkaian relay pada basis transistor, apakah terdapat tegangan Volt atau kondisi high (1) dan kaki kolektor pada transistor kondisi low (0) atau Volt. Apakah Led relay menyala sebagai indicator bahwa relay aktif atau tidak.

Tabel 1. Hasil IRDA dan Output P1.0-P1.4 Kondisi Normal

\begin{tabular}{|c|c|c|c|c|c|}
\hline \multirow{2}{*}{$\begin{array}{c}\text { Penekanan } \\
\text { Tombol }\end{array}$} & \multirow{2}{*}{$\begin{array}{c}\text { Titik B } \\
\text { (V) }\end{array}$} & \multicolumn{2}{|c|}{$\begin{array}{c}\text { Titik C } \\
\end{array}$} & \multirow{2}{*}{$\begin{array}{l}\text { Kondisi } \\
\text { Output }\end{array}$} & \multirow{2}{*}{$\begin{array}{c}\text { Level } \\
\text { tegangan }(\mathrm{V})\end{array}$} \\
\hline & & $\begin{array}{c}\text { Tegangan } \\
\text { (V) }\end{array}$ & $\begin{array}{l}\text { Arus } \\
(\mathrm{mA})\end{array}$ & & \\
\hline 1 & 5 & 4.7 & 26,1 & 0 & 0.03 \\
\hline 2 & 5 & 4.6 & 25 & 0 & 0.02 \\
\hline 3 & 5 & 4.6 & 24 & 0 & 0.03 \\
\hline 4 & 5 & 4.7 & 23 & 0 & 0.02 \\
\hline 5 & 5 & 4.7 & 26 & 0 & 0.03 \\
\hline Power & 5 & 4.6 & 25 & 0 & 0.03 \\
\hline
\end{tabular}

(Pada tabel 1)Ketika kondisi normal kaki 6 atau P3.2 pada mikrokontroler AT89C2051 adalah high yaitu \pm 4.7 Volt (titik C) dan output tegangan akan dalam kondisi low (0).

Tabel 2. Hasil IRDA dan Output P 1.0 - P 1.4 Kondisi Saat Penekanan Remote

\begin{tabular}{cccccc}
\hline $\begin{array}{c}\text { Penekanan } \\
\text { Tombol }\end{array}$ & $\begin{array}{c}\text { Titik B } \\
\text { (V) }\end{array}$ & \multicolumn{2}{c}{ Titik C } & $\begin{array}{c}\text { Kondisi } \\
\text { Output }\end{array}$ & $\begin{array}{c}\text { Level } \\
\text { tegangan } \\
\text { (V) }\end{array}$ \\
\cline { 3 - 4 } & & $\begin{array}{c}\text { Tegangan } \\
\text { (V) }\end{array}$ & $\begin{array}{c}\text { Arus } \\
(\mathbf{m A})\end{array}$ & & \\
\hline 1 & 5 & 3,5 & 19,4 & 1 & 4,3 \\
2 & 5 & 3,6 & 20,5 & 1 & 4,5 \\
3 & 5 & 3,4 & 17.6 & 1 & 4,2 \\
4 & 5 & 3,6 & 19,9 & 1 & 4,6 \\
5 & 5 & 3,3 & 16,2 & 1 & 4,5 \\
Power & 5 & 3,5 & 19 & 1 & 4,5 \\
\hline
\end{tabular}

(Pada tabel 2) Saat penekanan remote control mengakibatkan kondisi titik $\mathrm{C}$ atau kaki 6 pada mikrokontroler AT89C2051, yang mana awalnya kondisi high (1) atau $\pm 4,7$ volt menjadi $\pm 3,5$ volt saat penekanan remote control. Kemudian setelah remote control dilepas maka akan kembali pada keadaan awal yaitu $\pm 4,7$ volt. Sehingga mengakibatkan kondisi pada Port 1.0 akan high (1) dengan level tegangan $\pm 4,5$ Volt dan seterusnya sampai pada tombol 5. Namun apabila penekanan tombol Power maka kondisi output pada P1.0 
sampai P1.4 akan menjadi high dengan level tegangan $\pm 4,5$ Volt dan menekan tombol power kembali maka kondisi pada P1.0 sampai P1.4 akan menjadi Low (0).

Sinyal yang dikirimkan oleh transmitter dan diterima oleh IR demodulator. Jika transmitter mengirimkan sinyal on dan off maka pada receiver juga menerima sinyal on dan off. Tetapi receiver hanya mendeteksi ada carrier atau tidak. Jika ada data carrier maka pulsa yang dikirimkan adalah high sebaliknya jika tidak ada data carrier maka pulsa yang dikirimkan adalah low. Pada tabel 3 merupakan hasil jarak antara remote terhadap respon alat.

Tabel 3. Hasil Jarak Remote Terhadap Alat

\begin{tabular}{|c|c|c|}
\hline No. & $\begin{array}{c}\text { Jarak Remote } \\
\text { Terhadap Alat } \\
\text { ( meter) }\end{array}$ & $\begin{array}{c}\text { Respon Alat Terhadap } \\
\text { Penekanan Remote }\end{array}$ \\
\hline 1 & 1 & Diterima \\
\hline 2 & 3 & Diterima \\
\hline 3 & 6 & Diterima \\
\hline 4 & 9 & Diterima \\
\hline 5 & 12 & Diterima \\
\hline 6 & 13 & Tidak Diterima \\
\hline
\end{tabular}

Tabel 4. Hasil Sudut Remote Terhadap Alat

\begin{tabular}{|c|c|c|}
\hline No. & $\begin{array}{c}\text { Sudut Remote } \\
\text { Terhadap Alat }\end{array}$ & $\begin{array}{c}\text { Respon Alat Terhadap } \\
\text { Sudut Remote }\end{array}$ \\
\hline 1 & $90^{\circ}$ & Diterima \\
\hline 2 & $70^{\circ}$ & Diterima \\
\hline 3 & $50^{\circ}$ & Diterima \\
\hline 4 & $30^{\circ}$ & Diterima \\
\hline 5 & $10^{\circ}$ & Tidak Diterima \\
\hline 6 & $0^{\circ}$ & Tidak Diterima \\
\hline
\end{tabular}

Keterangan : sudut remote terhadap alat diambil dengan jarak 1 meter

\section{KESIMPULAN}

Kesimpulan secara menyeluruh dari rangkaian audio atau video selector 5 channel dengan mikrokontroler AT89C2051 yaitu memberikan kemudahan bagi pemilik pesawat televisi yang hanya memiliki satu input jack $\mathrm{A} / \mathrm{V}$.

\section{DAFTAR PUSTAKA}

[1] B.Brey Barry, "Mikroprosesor intel", Penerbit Erlangga, (2001).

[2] D. Chattopadhyay, P.C. Rakshit, B. Saha, N. N. Purkait, "Dasar Elektronika",

Penerbit Universitas Indonesia, (1989).

[3] Drs. Ganti Depari. Mpd, "Pokok-Pokok Elektronika", Penerbit M2S Bandung, (1987).
[4] Kenneth J.Ayala, "Architecture, Programming, and Aplication", Penerbit

Addison-wesley Publishing Company, (1995).

[5] Malvino, Hanapi Gunawan, "Prinsip-prinsip Elektronika Edisi kedua",

Erlangga,(1999).

[6] Millman dan Halkias, M. Barmawi dan M. O. Tjia, "Elektonika Terpadu

(Integrated Electronic) Rangkaian dan Sistem Analog dan Digital Jilid 1",

Erlangga, (1997).

[7] Soepono Soeparlan dan Umar Yahdi, "Teknik Rangkaian Listrik Jilid 1",

Penerbit Universitas Gunadarma, (1995).

[8] Samratul Fuady, Nehru, Gina Anggraeni. "Deteksi Objek Menggunakan Metode Single Shot Multibox Detector Pada Alat Bantu Tongkat Tunanetra Berbasis Kamera." Journal of Electrical Power Control and Automation, 3(2), (2020).

\section{Biodata Penulis}

Mhd Erpandi Dalimunthe, lahir di Serbelawan/09 Maret 1982. Alamat saat ini JIP 1 Blok VI No 43 Medan. Lulus S1 Teknik Elektro Universitas Gunadarma Tahun 2005. Lulus S2 Magister Teknik Elektro Gunadarma Tahun 2010. Lulus S2 Magister Keselamatan dan Kesehatan Kerja Universitas Indonesia Tahun 2012. Saat ini beraktifitas sebagai Dosen Prodi Teknik Elektro Universitas Pembangunan Panca Budi Medan. 